Research Article

\title{
Impacts of Sea Surface Temperature and Atmospheric Teleconnection Patterns in the Northern Mid-Latitudes on Winter Extremely Cold Events in North China
}

\author{
Liping Li $\mathbb{D}^{1,2}$ Wenjie Ni, ${ }^{1,2}$ Yige Li, ${ }^{3}$ Dong Guo, ${ }^{1,2}$ and Hui Gao ${ }^{4}$ \\ ${ }^{1}$ Collaborative Innovation Center on Forest and Evaluation of Meteorological Disasters, NUIST, Nanjing 210044, China \\ ${ }^{2}$ Key Laboratory of Meteorological Disaster (NUIST), Ministry of Education, Nanjing 210044, China \\ ${ }^{3}$ Xiyang County Meteorological Bureau, Xiyang, Shanxi 045300, China \\ ${ }^{4}$ National Climate Center, Beijing 100081, China \\ Correspondence should be addressed to Liping Li; li.liping@163.com
}

Received 27 August 2020; Revised 9 January 2021; Accepted 27 February 2021; Published 9 March 2021

Academic Editor: Olga Zolina

Copyright (c) 2021 Liping Li et al. This is an open access article distributed under the Creative Commons Attribution License, which permits unrestricted use, distribution, and reproduction in any medium, provided the original work is properly cited.

The frequency distribution of winter extreme cold events (ECEs) in North China and the influences of mid-latitude sea surface temperature anomalies (SSTAs) in the Northern Hemisphere are studied. The results show that (1) the frequency of single station ECEs (SSECEs) in winter increases from southeast to northwest, with a decrease before 2008 and then a significant increase. This trend abrupt change occurs in late winter. (2) When the SST in the North Pacific shows an "El-Niño-like" anomaly in winter, it triggers the negative Arctic Oscillation (-AO), positive Pacific North America (+PNA), and positive Eurasia Pacific (+EUP) atmospheric teleconnection patterns in the mid-lower troposphere. As a result, the ridge to south of Lake Baikal becomes stronger. Meanwhile, SST in the North Atlantic shows a "reversed C" negative anomaly with North Atlantic Oscillation (+NAO), (+PNA)like and (+EUP)-like patterns, and the ridge to southwest of Lake Baikal becomes stronger. Furthermore, both cause the Siberian High to become weaker in the north and stronger in the south. With the weaker East Asia subtropical jet and stronger East Asia winter monsoon, these factors lead to a significant increase of SSECE frequency in North China. (3) When the SSTA shows an "El Niño-like" developing pattern from summer to autumn in the North Pacific, the winter SSECE frequency will be higher. (4) The purported mechanism between the mid-latitude SSTA and the winter SSECE frequency in North China is the following: the SSTA in the North Pacific in summer and autumn excites atmospheric teleconnection wave trains, and the Atlantic stores these anomaly signals. In winter, the interaction between the SSTAs in the North Pacific and the North Atlantic enhances the Eurasian teleconnection wave train. With the upstream fluctuation energy dispersing downstream, the wave train centers move eastward with the season, resulting in an increase in the frequency of the SSECEs.

\section{Introduction}

According to the sixth special report of the Intergovernmental Panel on Climate Change (IPCC), the increase in global mean surface temperature (GMST) reached $0.87^{\circ} \mathrm{C}$ in 2006-2015 [1]. Under the background of global warming, extreme cold events (ECEs), such as freezing rain and snow [2], extreme low temperatures [3-5], and persistent low temperatures [6], are more frequent and threaten people's lives and property. It is important to study extreme weather events in North China as a major area of agricultural economic development and an important transportation hub in China $[7,8]$.

The frequency and intensity of winter ECEs in Northern China are vulnerable to the winter monsoon circulations systems [9-12]. Ding [9] studied the formation and spread of the Siberian High and its relationship with cold waves in East Asia. In winter, the intensification and northward extension of the Urals blocking high and the positive longitude anomaly of the North Atlantic storm track can strengthen the Siberian High and deepen the East Asian trough, which cause persistent low-temperature events in East Asia 
$[5,10,11]$. However, the frequency of cold waves does not increase monotonically with the strengthening of the Siberian High [12]. ECEs occur when Siberian High and the Aleutian Low are both strong [13] and are related to the location of these two systems [14]. Furthermore, Tao [15] divided the paths of cold waves invading China into a northwest path, a superpole cold wave path, and a southward invasion path of cold air from the east of Lake Baikal. Different cold air paths correspond to different configurations of atmospheric systems. Besides, the frequency before 2008 has obviously decreased $[16,17]$, while it is closely related to the weakening of the East Asian winter monsoon and the warming of the low-level cold air stack, especially in the Inner Mongolia, North China, and Jianghuai areas $[4,12,18]$. At the same time, the interaction between the East Asian subtropical jet and temperate jet is an important factor affecting the winter ECEs in China [19].

ECEs are also related to atmospheric teleconnection, e.g., the Arctic Oscillation (AO) and the North Atlantic Oscillation (NAO) [20-26]. The AO affects the Siberian High by modulating quasi-stationary planetary waves. When the AO is in a positive phase, the East Asian trough, Siberian High, and East Asian winter monsoon are weaker, and the temperature in China is higher [20-24]. In winter, when the $\mathrm{NAO}$ is in a positive phase, the temperature in China is higher $[25,26]$. In addition, external forcing anomalies such as SSTAs also have important effects on the winter temperature in China. For example, the El Niño-Southern Oscillation (ENSO) $[27,28]$, SSTAs in the tropical Indian Ocean [29], Kuroshio Sea areas [30], North Pacific [31], and North Atlantic [31] all have strong correlations with the winter temperature in China.

In summary, there have been many studies on atmospheric circulation and external forcing anomalies affecting the winter temperature in China or North China. In recent years, cold waves in the mid-latitudes of Eurasia have been frequent and persistent [32]. North China is one of the regions most affected by cold waves, and it is necessary to further research the new characteristics and possible causes of ECEs, such as cold waves in North China. In this paper, the temporal and spatial characteristics of the winter ECE frequency in North China since 1980 are analyzed, and the influence of the mid-latitude SSTA and its atmospheric teleconnection patterns in the Northern Hemisphere on the interannual anomalies of ECE is emphasized, to identify interannual prediction signals and provide a reference for short-term climate prediction in North China.

\section{Data and Methods}

2.1. Data and Preprocessing. The data include (1) daily minimum temperatures at 2,480 stations provided by the National Climate Center in China; (2) the NCEP/NCAR monthly sea-level pressure field, the $850 \mathrm{hPa}$ temperature and wind fields, the $200 \mathrm{hPa}$ zonal wind field, and the $500 \mathrm{hPa}$ geopotential height field, with a resolution of $2.5 \times 2.5$ [33]; and (3) the NOAA monthly SST, with a resolution of $1 \times 1$ [34]. The data are for the 1980-2016 period.
North China is defined as the study region $\left(35^{\circ}-42.5^{\circ} \mathrm{N}\right.$, $110^{\circ}-120^{\circ} \mathrm{E}$ ). To ensure the continuity and integrity of the data, the stations from which the missing data of the daily minimum temperature does not exceed $1 \%$ are retained. Excluding the high mountain stations which are higher than $2500 \mathrm{~m}, 421$ stations are finally selected. The distribution is shown in Figure 1.

2.2. Methods. Based on the regulations of "Cold Air Level" (GB/T 20484-2017) and "Cold Wave Level" (GB/T 219872017) published by the National Meteorological Center of China Meteorological Administration in 2017, a single station extreme cold event (i.e., a single station cold wave) is defined by a daily minimum air temperature lower than and equal to $4^{\circ} \mathrm{C}$ and either one of three conditions: a decrease by no less than $8^{\circ} \mathrm{C}$ within 24 hours, or a decrease by no less than $10^{\circ} \mathrm{C}$ within 48 hours, or a decrease by no less than $12^{\circ} \mathrm{C}$ within 72 hours. For convenience, an extremely cold event can be abbreviated as an ECE, with a single station ECE as a SSECE.

The frequency of winter ECEs in a given year is the total number of ECEs occurring from December to February of the following year.

In this paper, statistical analysis methods including correlation, composite analysis, and linear regression are mainly used. Student's $t$-test method is used to determine the statistical significance of the correlation coefficients and linear trend.

\section{The Spatial and Temporal Characteristics of the ECE Frequency in Winter in North China}

\subsection{Single Station ECEs}

3.1.1. Spatial Distribution. The multi-year average of the SSECE frequency during the period of 1980 to 2016 is calculated (Figure 2). The frequency of SSECEs increases from southeast to northwest in winter. More than 4 SSECEs occurred in western Inner Mongolia, northern Shanxi, northeastern Shaanxi, northwestern Hebei, and northern Liaoning, with the maximum frequency 8 in western Inner Mongolia (Figure 2(a)). The frequency distribution of SSECEs in December (Figure 2(b)), January (Figure 2(c)), and February (Figure 2(d)) is similar to that in winter.

3.1.2. Temporal Variations. The regional averages of the SSECE frequency in North China are calculated for the winters of 1980-2016. According to the statistical results, the 1.92 SSECEs occurred per winter on average, and the maximum (minimum) value is 3.4 (0.8) in 2008 (2007), with larger interannual differences. The average frequency is 0.64 , 0.66 , and 0.62 per year in December, January, and February, with the maximum (minimum) value being 1.94 (0.16), 1.31 (0.09), and 1.10 (0.17), respectively.

The frequency of SSECEs in winter decreases from 1980 to 2007 (Phase I) and increases significantly from 2009 to 2016 (Phase II) (Figure 3(a)). The frequency of SSECEs in January (Figure 3(c)) and February (Figure 3(d)) shows an 


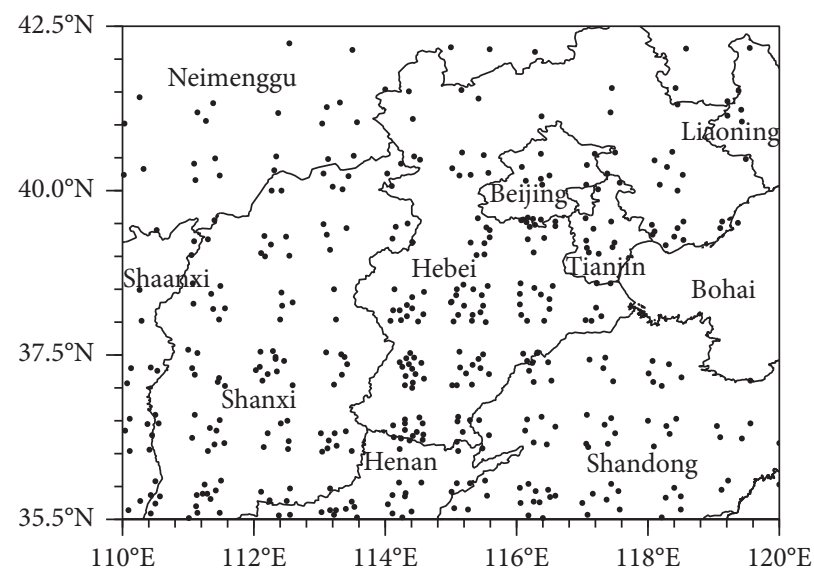

FIGURE 1: Distribution of 421 observation stations in North China.

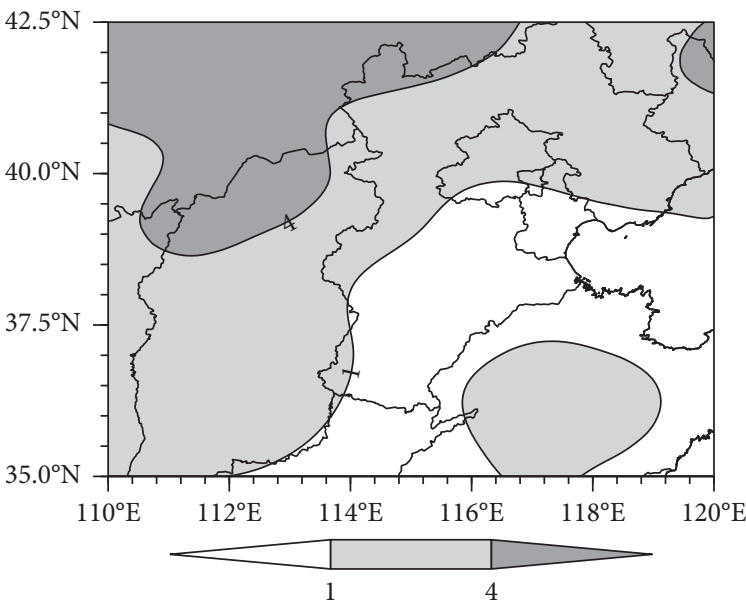

(a)

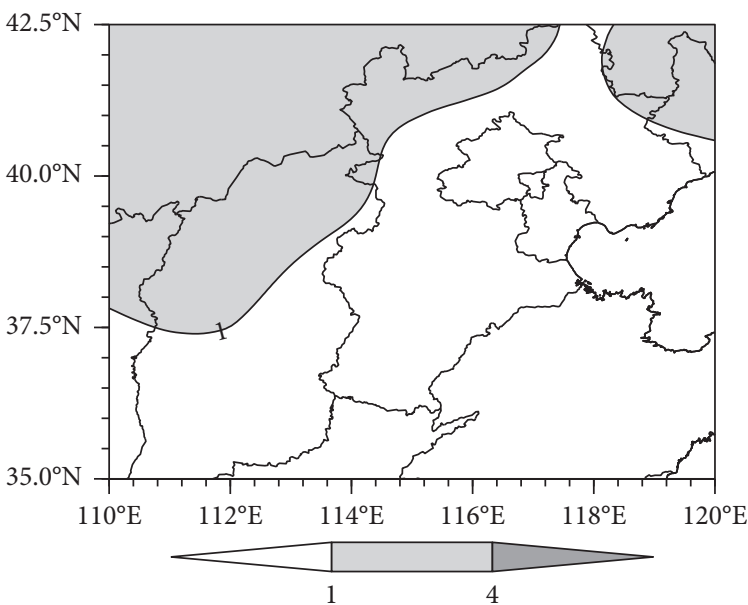

(c)

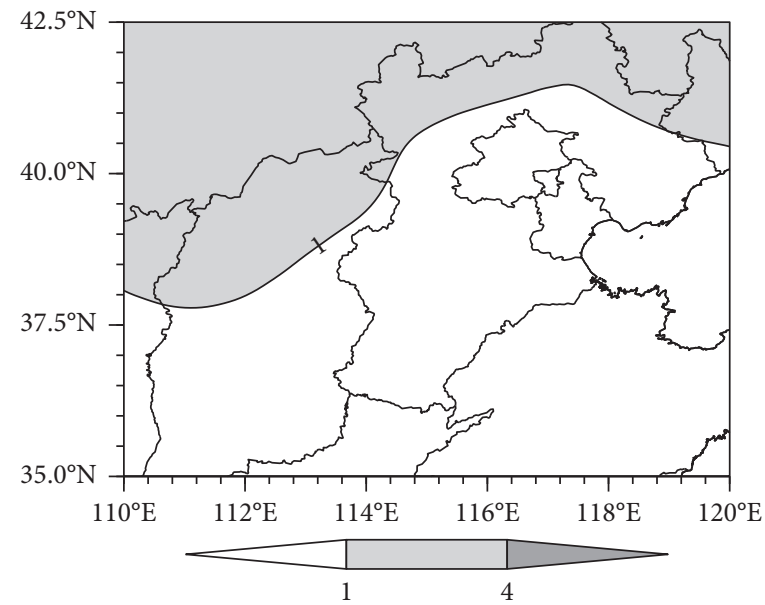

(b)

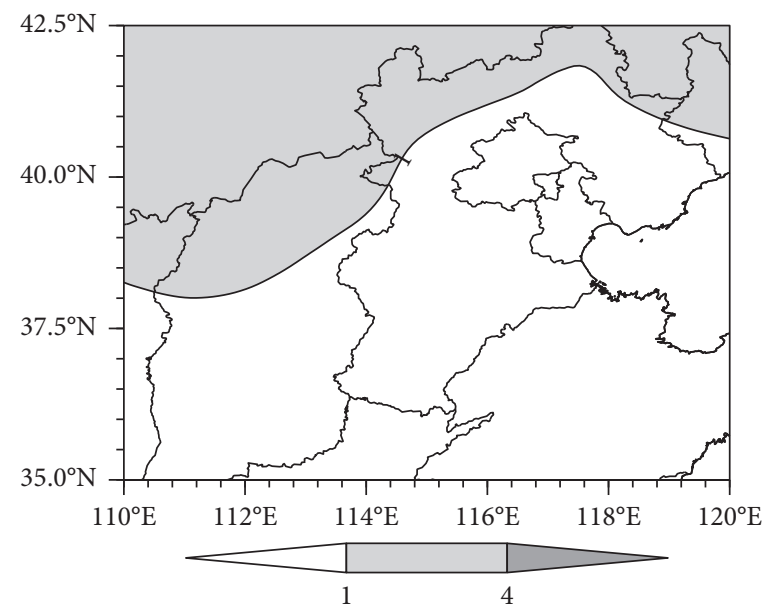

(d)

FIGURE 2: Spatial distribution of the multi-year average frequency of SSECEs in North China in winter (a), December (b), January (c), and February (d). Unit: number of occurrences. 


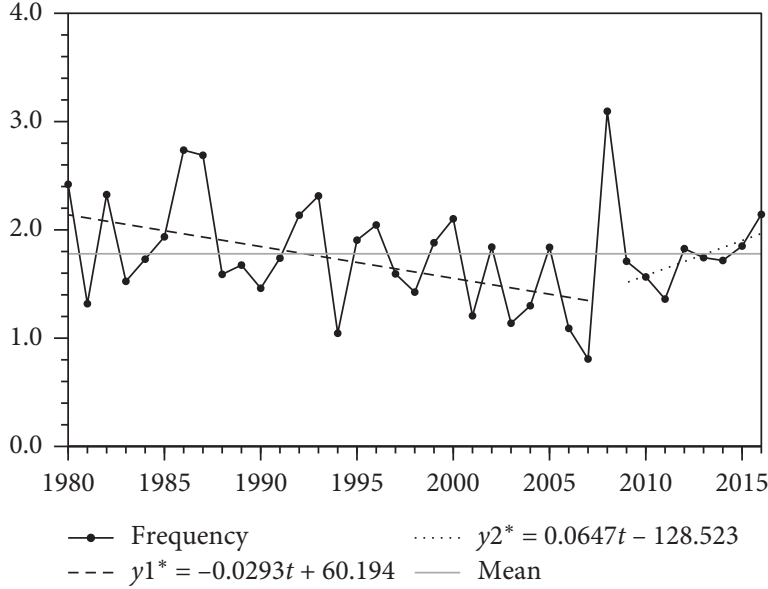

(a)

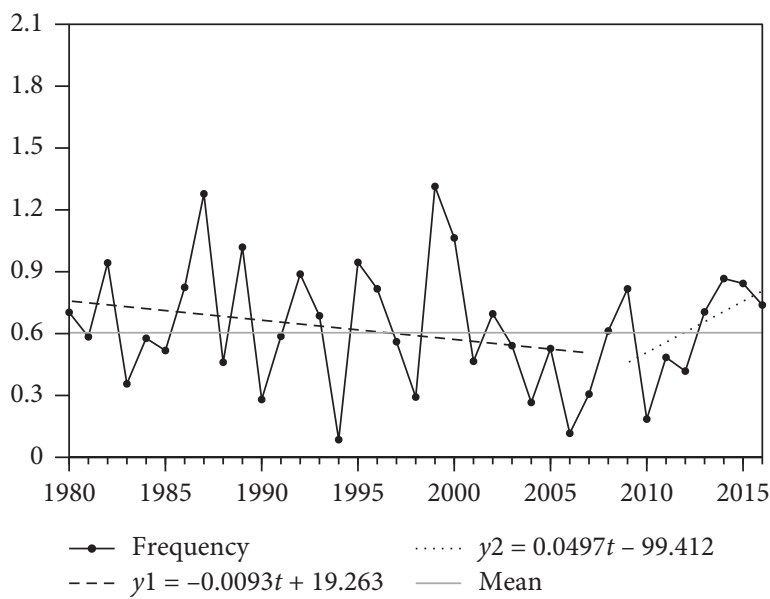

(c)

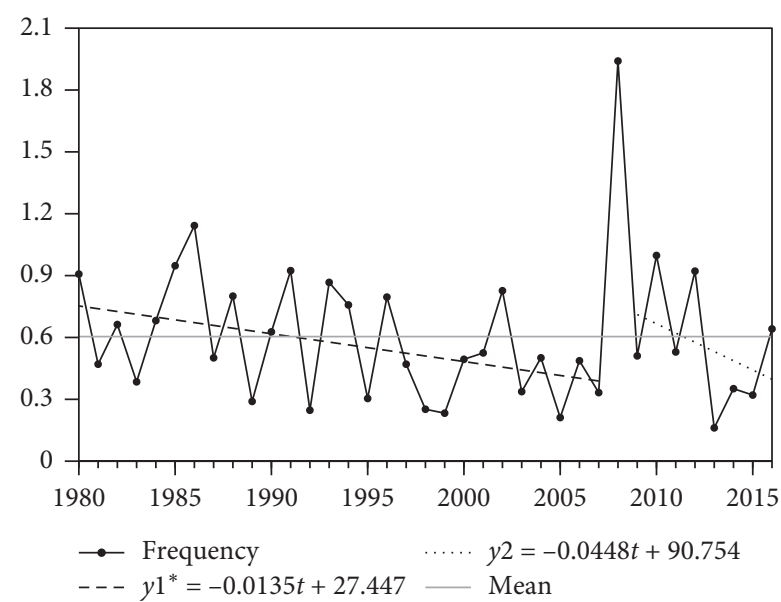

(b)

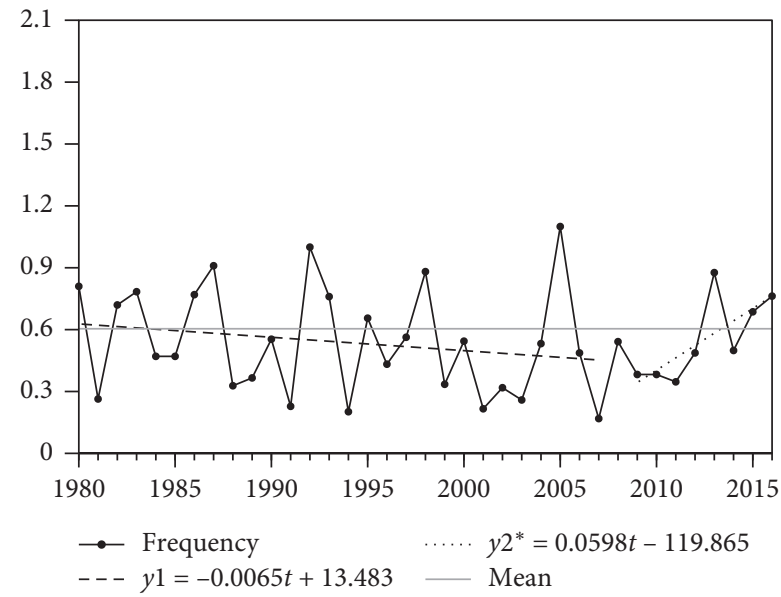

(d)

FIgURE 3: The regional average series of the SSECE frequency (solid line) and its linear trend (dotted line) in North China in winter (a), December (b), January (c), and February (d) from 1980 to 2016 (unit: number of occurrences). One asterisk * represents significance at the 95\% confidence level using Student's $t$-test.

abrupt trend similar to that in winter. However, December (Figure 3(b)) is an exception in that the frequency still decreases in Phase II. Therefore, the abrupt change in the SSECE frequency in winter is mainly caused by the SSECEs in later winter (January and February). Why is the frequency trend in December different from that in winter? It is worth further study.

Figure 4 further shows the regional distribution of the linear trend of the SSECE frequency. Except for the junction of southwest Shanxi and Shaanxi, the frequency of the SSECEs decreases significantly in most areas of North China in Phase I in winter (Figure 4(a)). In Phase II (Figure 4(e)), except for a significant increase at the junction of the southwest of Inner Mongolia, and central and western Shanxi and Shaanxi, most areas show a decrease. The trends of the SSECE frequency in December (Figure 4(b)), January (Figure 4(c)), and February (Figure 4(d)) in Phase I are similar to those in winter, but the significant areas of the trend are slightly different. In Phase II, the frequency decreases over the entire region in December (Figure 4(f)) but increases in most areas in January (Figure 4(g)) and February (Figure $4(\mathrm{~h})$ ). The high value areas are located at the junction of central and western Shanxi, Shaanxi, and Inner Mongolia, which indicates once again that the increase in the SSECE frequency in winter in Phase II is caused by those in later winter (January and February).

\section{The Influence of Mid-Latitude SSTA on the Winter SSECE Frequency in North China}

Previous research suggested that the mid-latitude SSTA in the Northern Hemisphere has a significant influence on the winter temperature in China [30,31]. How are the anomalies of the mid-latitude SST in the Northern Hemisphere related to the frequency of the SSECEs in North China in winter? Moreover, what kind of anomalous patterns of atmospheric circulation is caused by the SSTA? Through the study of these questions, this paper attempts to reveal the possible causes for the frequent ECEs in North China. It also looks for its possible interannual prediction signals, to provide a 


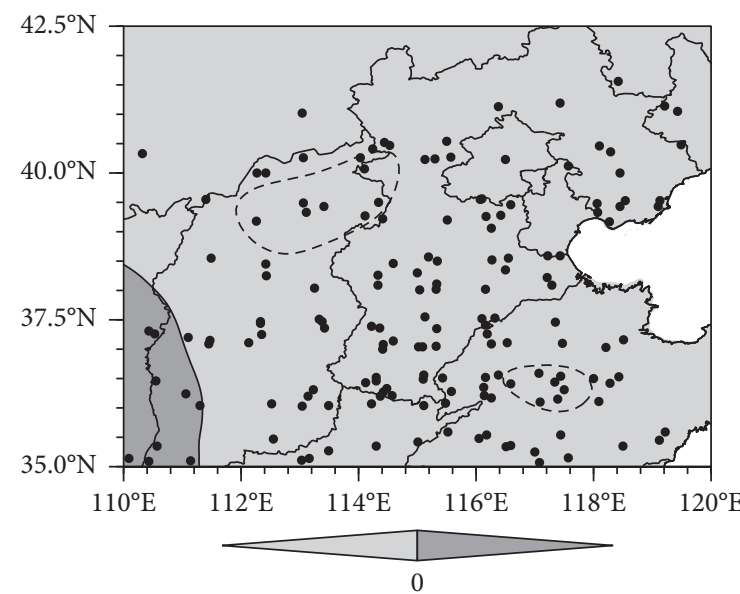

(a)

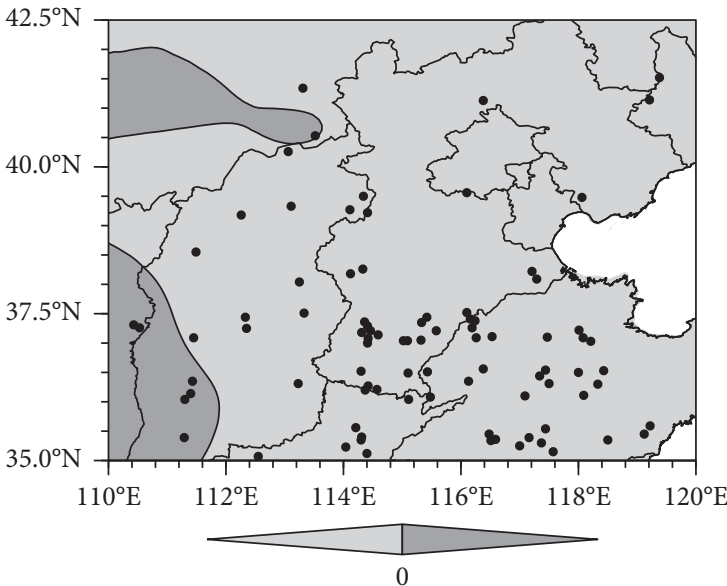

(c)

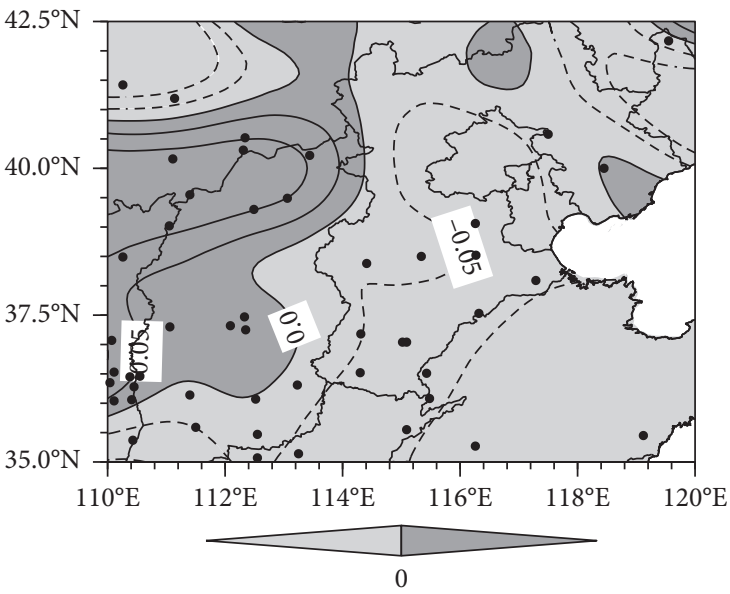

(e)

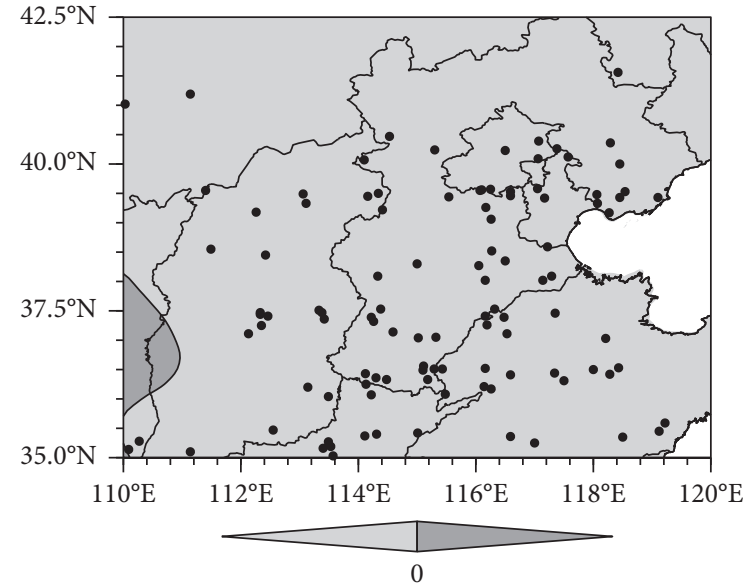

(b)

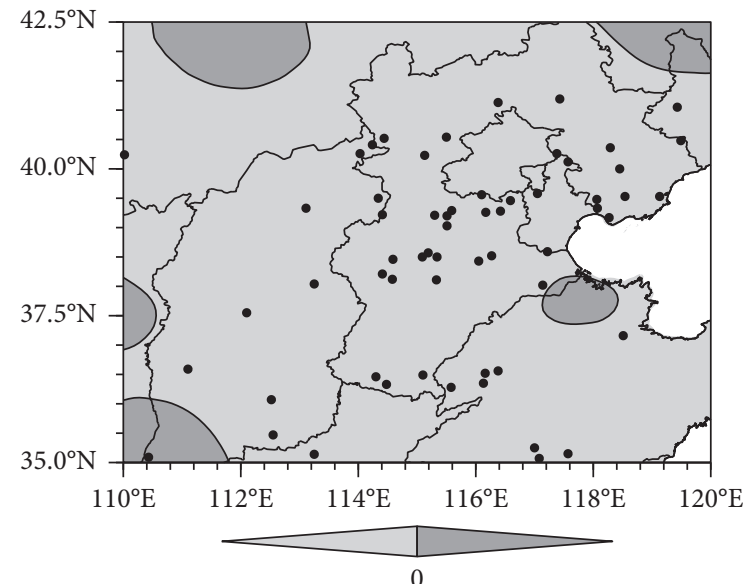

(d)

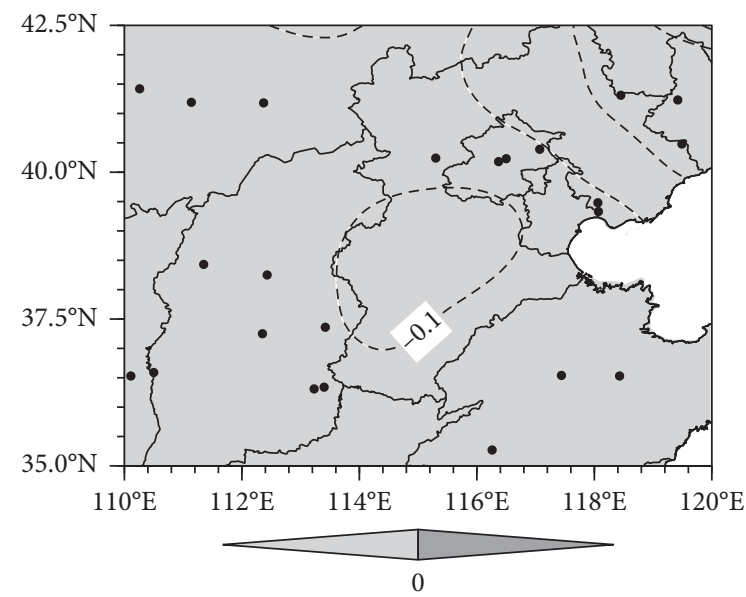

(f)

Figure 4: Continued. 


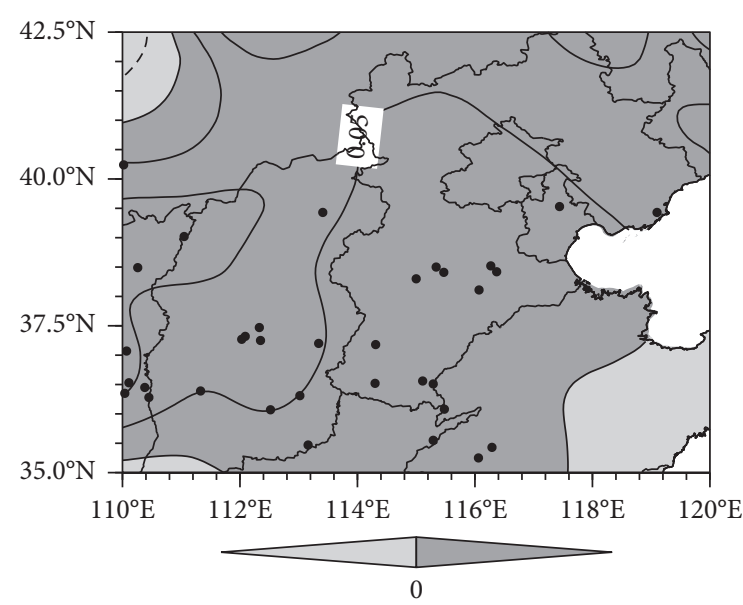

(g)

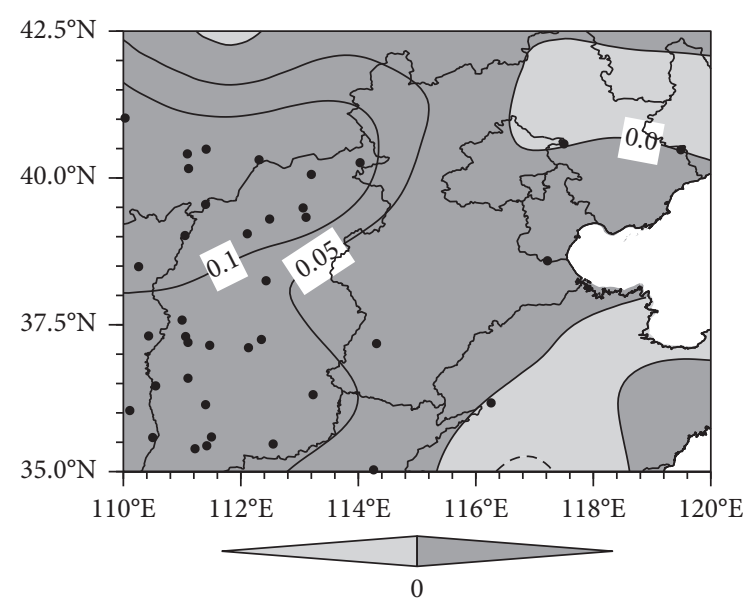

(h)

Figure 4: The linear trend distribution of the SSECE frequency in winter (a, e), December (b, f), January (c, g), and February (d, h) in North China during the periods of 1980-2007 (left) and 2009-2016 (right); unit: number of occurrences/a, areas shaded with black dots represent significance at the 90\% confidence level using Student's $t$-test. (a) Winter_phase I (1980-2007), (b) Dec_phase I (1980-2007), (c) Jan_phase I (1980-2007), (d) Feb_phase I (1980-2007), (e) Winter_phase II (2009-2016), (f) Dec_phase II (2009-2016), (g) Jan_phase II (2009-2016), and (h) Feb_phase II (2009-2016).

reference for short-term climate prediction in North China. The first question will be studied in Section 4.1, and the second will be discussed in Sections 4.2 and 4.3.

4.1. The Relationship between SSTA and SSECE Frequency. Figure 5 shows the lead-lag and contemporaneous correlation coefficients between the regional average frequency of the winter SSECEs (Figure 3(a)) and SSTA over the northern hemisphere in spring, summer, autumn, and winter, respectively. According to Figure 5, the significant correlation area in the North Pacific is too small in spring, so we select the key areas in summer, autumn, and winter. For the North Atlantic, the correlation coefficient between the regional average SSTA in the significant correlation areas in spring (Figure 5(a)) and the regional average frequency of the winter SSECEs in North China is not statistically significant, and the significant correlation areas are too small in summer and autumn, so we select the key areas in winter. For convenience, the significant correlation areas of each season in Figure 5 are indicated by the boxes labeled A, B, and C. A is the region $\left(8-15^{\circ} \mathrm{N}, 145-175^{\circ} \mathrm{E}\right), \quad B$ is $\left(25-45^{\circ} \mathrm{N}\right.$, $\left.180^{\circ}-200^{\circ} \mathrm{W}\right)$, and $\mathrm{C}$ consists of three subareas of $\left(55-60^{\circ} \mathrm{N}\right.$, $\left.15-50^{\circ} \mathrm{W}\right),\left(30-50^{\circ} \mathrm{N}, 11-20^{\circ} \mathrm{W}\right)$, and $\left(20-25^{\circ} \mathrm{N}, 20-50^{\circ} \mathrm{W}\right)$.

The correlation coefficient between the regional average SSTA over the above significant correlation area of the North Pacific and the Niño3 SST index in winter is -0.52 , which represents statistical significance at the $99 \%$ confidence level using Student's $t$-test. The significant correlation areas are positive in the east and negative in the west of the North Pacific in Figure 5(d), which is similar to an El Niño pattern over the tropical Pacific. Because the two patterns appear in different parts of the ocean, the SSTA pattern over the North Pacific in Figure 6(d) is called the "El Niño-like" pattern for convenience, while the SSTA in summer and autumn is collectively called the "developing El Niño-like" pattern.

To further understand the correlation relationships between SSTA and the frequency of the SSECEs, the SST indices of North Pacific and North Atlantic for each season are defined as $I_{\mathrm{NP}}$ and $I_{\mathrm{ATL}}$, respectively. That is, the regional average series of the SSTA over the significant correlation area from 1980 to 2016 is calculated and is then standardized as SST index series. If the significant correlation area contains two or more subareas, the subareas will be combined and considered as one. The correlation coefficients between these indices for each season and the regional average frequency of the winter SSECEs are calculated, and those with statistical significance at the $95 \%$ or $99 \%$ confidence level are listed in Table 1. When the SST in these key sea areas is anomalously cold (warm) in the corresponding seasons, the SSECEs in North China tend to be more (less) frequent in winter. The SSTA in the key areas of the North Pacific in summer and autumn has predictive significance for the winter SSECEs in North China.

The SSTAs over the North Pacific and North Atlantic key areas in winter are both negatively correlated with the winter SSECE frequency. Furthermore, the partial correlations among them are calculated, and whether the SSTAs of the two key areas influence each other is analyzed. The partial correlation coefficient between $I_{\mathrm{NP}}, I_{\mathrm{ATL}}$ and the regional average frequency of the winter SSECEs in North China are -0.29 and -0.41 , respectively. The corresponding the correlation coefficient in Table 1 is -0.43 and -0.48 , respectively. Therefore, the partial correlation coefficient for the North Atlantic SST changes very little, and their absolute value obviously decreases for the North Pacific SST but is still statistically significant at the $95 \%$ confidence level. Therefore, it can be concluded that the impacts of the SST over the two key areas on the winter SSECE frequency in 


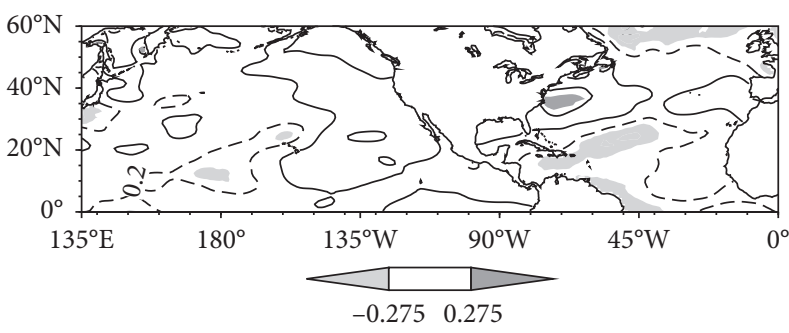

(a)

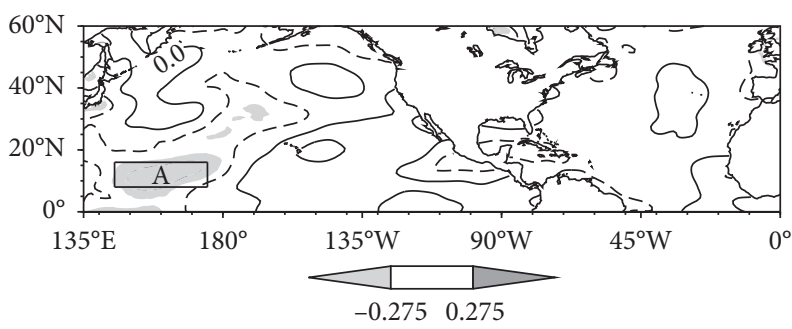

(c)

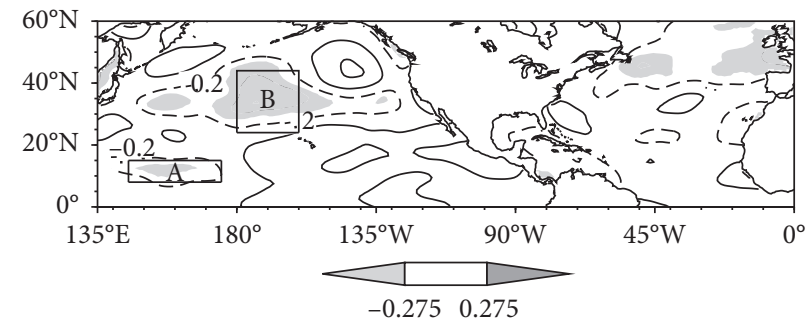

(b)

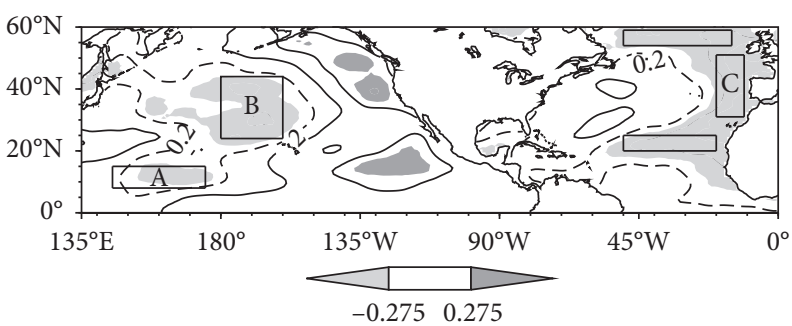

(d)

Figure 5: The lead-lag and contemporaneous correlation coefficients between the frequency of the winter SSECEs in North China and the SSTA in spring (a), summer (b), autumn (c), and winter (d). Shaded areas represent statistical significance at the $90 \%$ confidence level using Student's $t$-test and the rectangles with A, B, and C are the SST key areas.

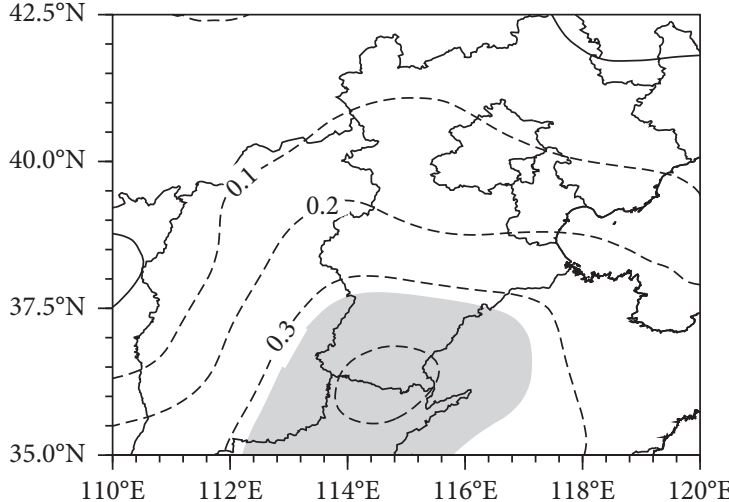

(a)

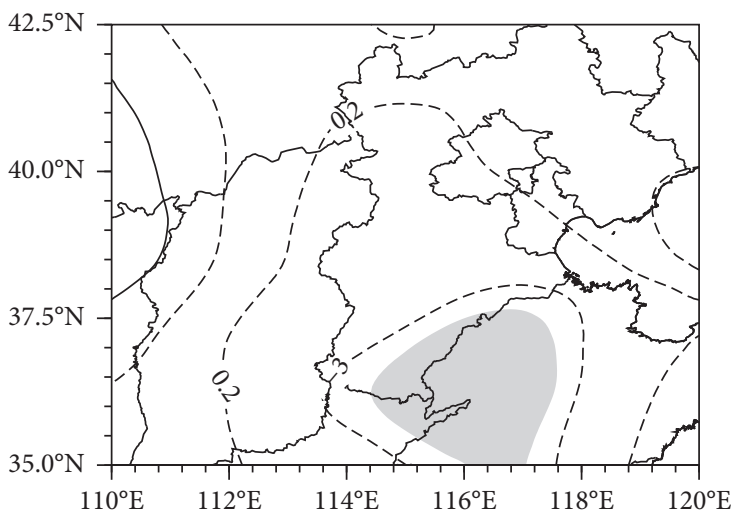

(c)

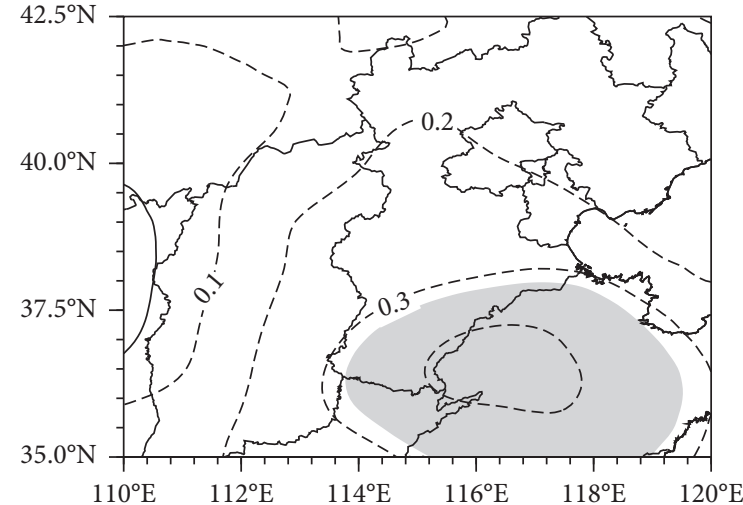

(b)

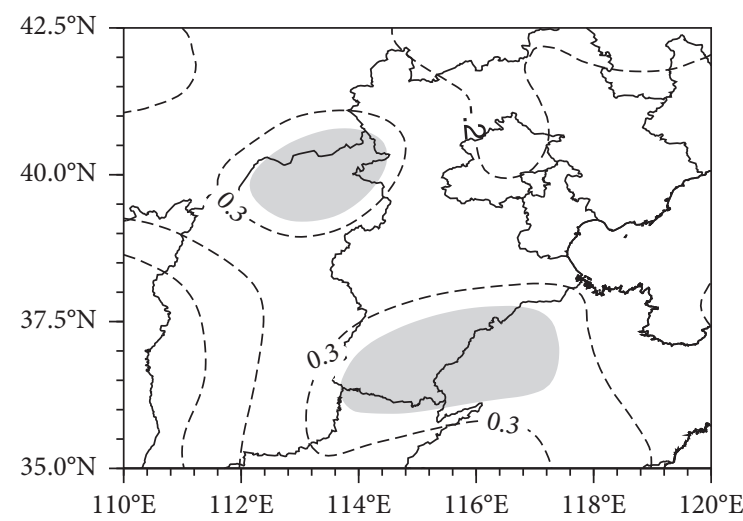

(d)

Figure 6: Correlation coefficients between $I_{\mathrm{NP}}$ in summer (a), fall (b), and winter (c), $I_{\mathrm{ATL}}$ in winter (d) and the SSECE frequency in North China in winter. The shaded regions represent statistical significance at the $90 \%$ confidence level using Student's $t$-test. 
TABLE 1: The lead-lag and contemporaneous correlation coefficients between $I_{\mathrm{NP}}$ and $I_{\mathrm{ATL}}$ of key areas in each season and the regional average frequency of the winter SSECEs in North China.

\begin{tabular}{lccc}
\hline SST index & Summer & Fall & Winter \\
\hline$I_{\mathrm{NP}}$ & $-0.35^{*}$ & $-0.44^{* *}$ & $-0.43^{* *}$ \\
$I_{\mathrm{ATL}}$ & - & - & $-0.48^{* *}$ \\
\hline
\end{tabular}

Note: ${ }^{*}$ and ${ }^{* *}$ represent statistical significance at the $95 \%$ or $99 \%$ confidence level using Student's $t$-test, respectively.

North China are relatively independent but have a certain combined effect.

In order to further understand the regional correlation distribution between the SST indices of the North Pacific and North Atlantic and the winter SSECE frequency in North China, Figure 6 shows the coefficient distribution among $I_{\mathrm{NP}}$ in summer, autumn, winter, $I_{\mathrm{ATL}}$ in winter and the winter SSECE frequency in North China. According to Figure 6, the significant negative correlation areas between $I_{\mathrm{NP}}$ and the frequency are mainly located in the south-central part of North China, namely, the junction areas of Hebei, Shanxi, Henan, and Shandong (Figures 6(a)-6(c)). The $I_{\mathrm{ATL}}$ has a significant negative correlation with the frequency not only in the regions mentioned above but also in the north-central part of North China (Figure 6(d)).

4.2. The Response of Atmospheric Circulation to the North Pacific SSTA. To understand how the SSTA in the North Pacific and North Atlantic affects the atmospheric circulation anomalies and thus the frequency of the SSECEs in North China in winter, the following section will analyze the linear regression coefficients of $I_{\mathrm{NP}}$ in summer, fall, and winter (Section 4.2) and $I_{\mathrm{ATL}}$ in winter (Section 4.3) on the atmospheric circulation factors in winter in the Northern Hemisphere, respectively.

4.2.1. Summer. Figure 7 shows the linear regression coefficients between $I_{\mathrm{NP}}$ in summer and the atmospheric circulation variables in winter. To facilitate understanding of the circulation anomalies when the SST in the key areas is anomalously cold and the SSECE frequency in winter in North China is high, all regression coefficients in Figure 7 are multiplied by -1 , and similar processing is done in Figures 8-10.

As seen in Figure 7, when the SST in the tropical northwest Pacific in summer is anomalously cold (Figure 5(b)), the sea level pressure (SLP) field in winter (Figure 7(a)) is likely to show an (-AO) anomalous pattern. Eurasia has an anomalous pressure gradient force, with its direction from polar region to the mid-high latitudes, which strengthens the meridional circulation and is conducive to the southward movement of cold air in the polar region. The PNA wave train shows a pattern "-" "+" "-" "+" starting in the North Pacific to North America, while in the North Atlantic to Eurasia, the wave train shows a pattern "+" "-" "+" "-". The two wave trains converge in the subtropical northwest Atlantic and cause a north-negative and southpositive anomalous distribution from the Eurasian mid-high latitudes $\left(50-80^{\circ} \mathrm{N}\right)$ to the southeast side of Lake Balkhash, which is similar to the empirical orthogonal function (EOF) second mode of the interannual anomaly of the Siberian High developed by Zhu et al. [35]. Its interaction with the Aleutian Low located southwest of the normal position produces a strong East Asian winter monsoon (Figure 7(e)).

The circulation patterns of the $500 \mathrm{hPa}$ geopotential height field $\left(\mathrm{H}_{500}\right.$, Figure $\left.7(\mathrm{~b})\right)$ and SLP field (Figure $7(\mathrm{a})$ ) basically show a quasi-barotropic structure in the midhigh latitudes. The Urals ridge is stronger, and the East Asian trough is toward the west and south. A cold air stack in the $850 \mathrm{hPa}$ temperature anomalous field $\left(\mathrm{T}_{850}\right)$ lies near Greenland, which provides conditions for the southward eruption of cold air (Figure 7(c)). The East Asia temperate jets and the subtropical jets in the $200 \mathrm{hPa}$ zonal wind field $\left(\mathrm{U}_{200}\right)$ over the Middle East to the Qinghai-Tibet Plateau are weaker (Figure $7(\mathrm{~d})$ ) and conducive to moving southward for the northwest air flow in front of the Urals ridge and behind the East Asian trough, which leads the $850 \mathrm{hPa}$ low-level cold air $\left(\mathrm{UV}_{850}\right)$ to North China through Greenland, Novaya Zemlya, and the west side of Lake Baikal (Figure 7(e)) and causes frequent SSECEs in North China.

4.2.2. Fall. When the negative SSTA expands from the tropical northwest Pacific to the central North Pacific in fall (Figure 5(c)), the (-AO), (+PNA)-like, and (+EUP)like quasi-barotropic teleconnection patterns or wave trains in the middle and lower troposphere (Figures 8(a) and $8(\mathrm{~b}))$ are more prominent. The north-south seesaw anomaly of the Siberian High is clearer (Figure 8(a)), the ridge previously located in the Urals (Figure $7(\mathrm{~b})$ ) moves to between Lake Balkhash and Lake Baikal (Figure 8(b)), and the cold air stack between Greenland and Severnaya Zemlya is further strengthened (Figure $8(\mathrm{c})$ ), as is the stronger temperate jet and weaker subtropical jet (Figure 8(d)). All of these are favorable for the cold air to arrive in North China along Western Europe, the East European Plain, West Siberia, and the west of Lake Baikal (Figure 8(e)).

4.2.3. Winter. In winter, along with the formation of an "El Niño-like" pattern in the North Pacific (Figure 5(d)), the atmospheric circulation anomalies (Figure 9) continue developing and are very similar to those in autumn (Figure 8). However, the anomalies of the system centers are stronger, e.g., the $(-\mathrm{AO}),(+\mathrm{PNA})$, and (+EUP) teleconnection patterns or wave trains (Figure 9(a) and 9(b)), leading to stronger meridional circulation. Meanwhile, there are stronger temperate and weaker East Asian subtropical jets (Figure 9(d)), stronger low-level cold air stacks in the vicinity of Novaya Zemlya (Figure 9(c)), and stronger East Asian winter monsoons (Figure 9(e)). The above circulation anomalies are all favorable for cold air to invade North China from Novaya Zemlya, the East European Plain, the Caspian Sea, West Siberia, and Lake Baikal (Figure 9(e)), resulting in frequent ECEs in North China. 


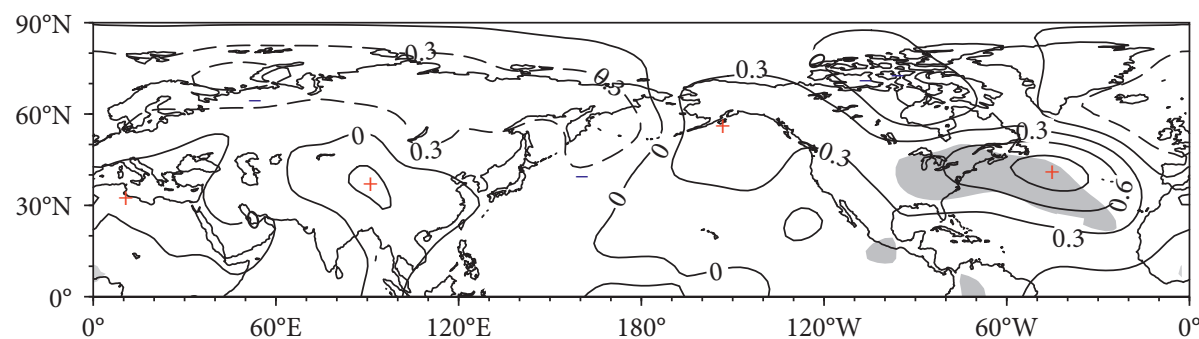

(a)

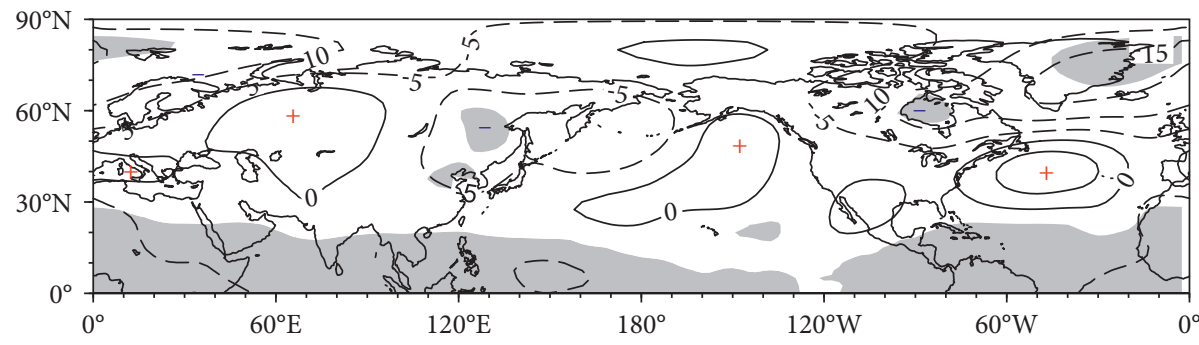

(b)

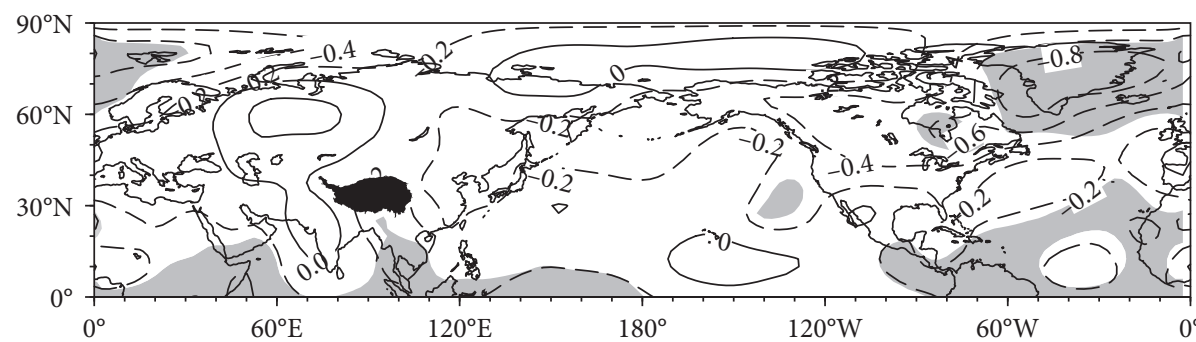

(c)

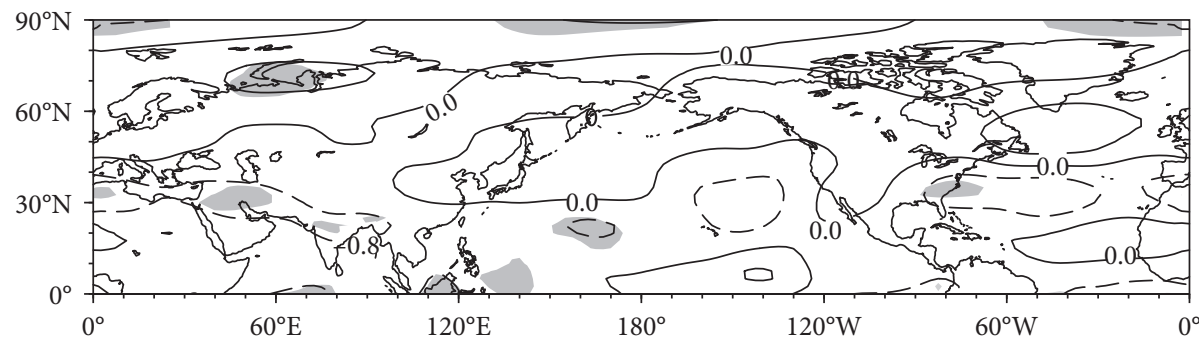

(d)

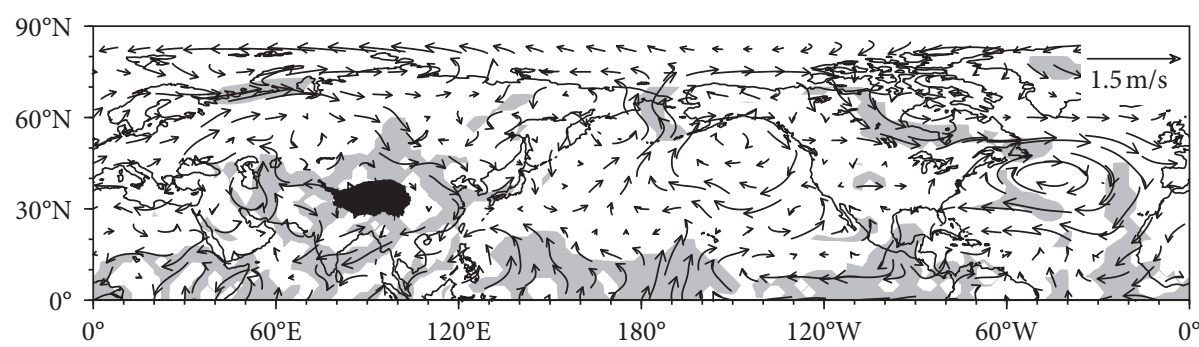

(e)

FIGURE 7: Linear regression coefficients of $I_{\mathrm{NP}}$ in summer on the SLP field (a) unit: $\mathrm{hPa}, \mathrm{T}_{850}$ (b) unit: ${ }^{\circ} \mathrm{C}, \mathrm{H}_{500}$ (c) unit: gpm, UV $\mathrm{VV}_{850}$ (d) unit: $\mathrm{m} / \mathrm{s}$, and $U_{200}$ (e) unit: $\mathrm{m} / \mathrm{s}$ in winter. All values are multiplied by -1 , and shaded areas represent statistical significance at the $90 \%$ confidence level using Student's $t$-test. 


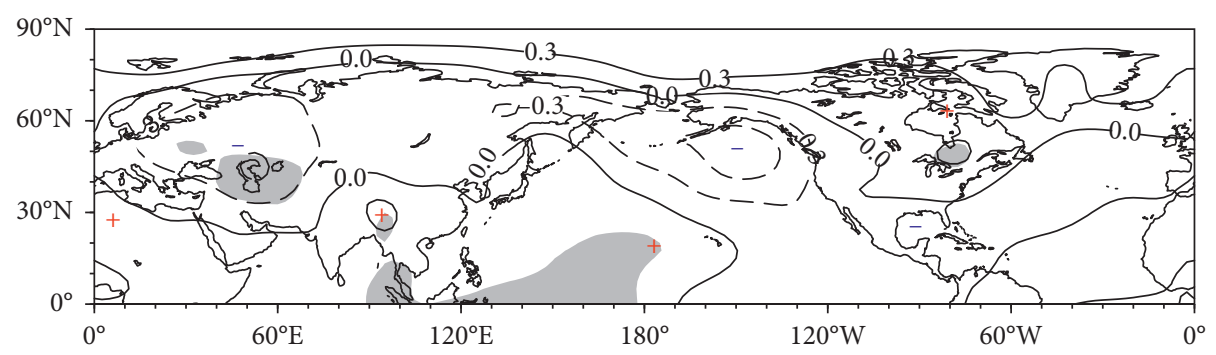

(a)

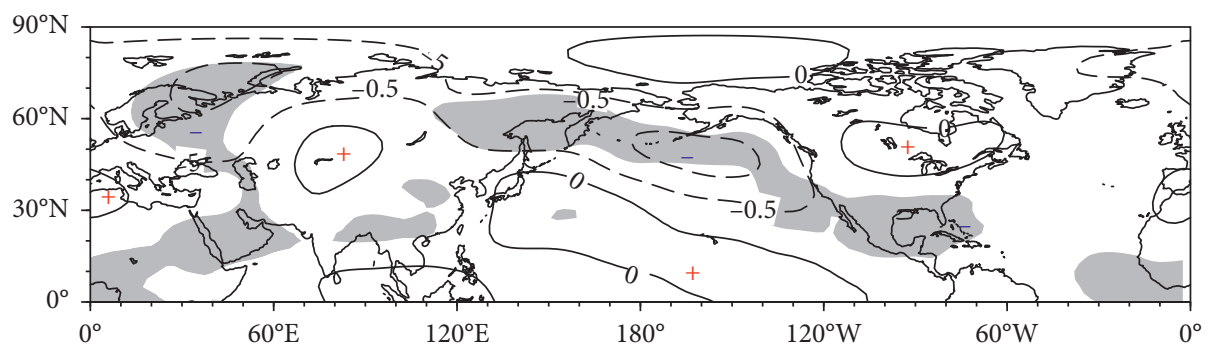

(b)

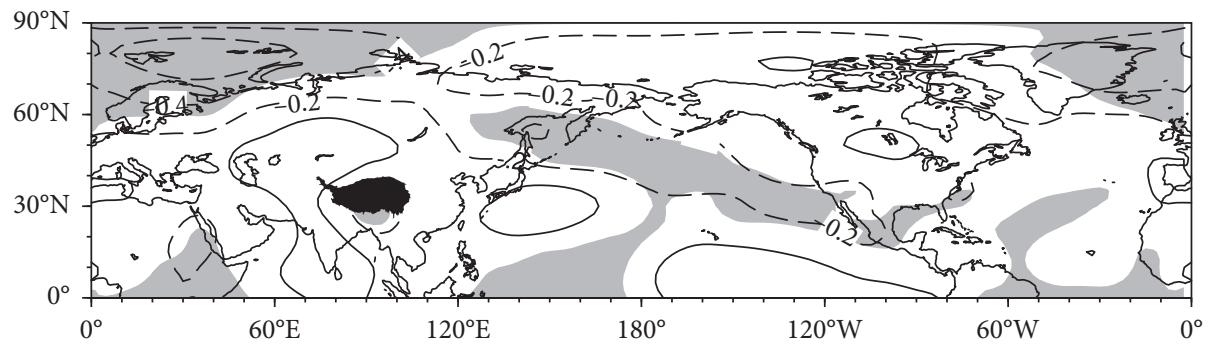

(c)

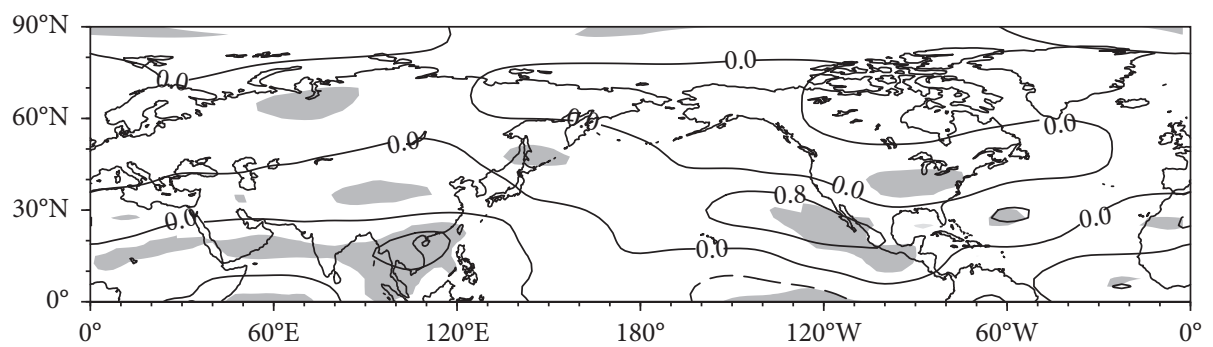

(d)

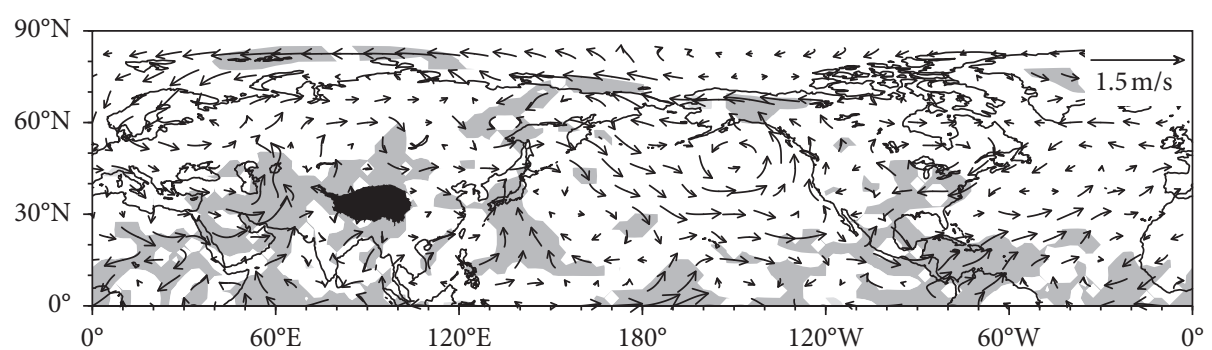

(e)

FIgURe 8: The same as in Figure 7 but for $I_{\mathrm{NP}}$ in autumn.

4.3. The Response of Atmospheric Circulation to the North Atlantic SSTA. Except for (+NAO) rather than (-AO), the circulation anomalies in the Pacific, North America, and Eurasia that are excited by the "reversed C" negative SSTA in the North Atlantic in winter (Figure 10) are very similar to those excited by the "El Niño-like" SSTA in the North Pacific (Figure 9). The atmospheric circulation displays "(+PNA)like" and "(+EUP)-like" quasi-barotropic teleconnection wave trains in the mid-lower troposphere (Figures 10(a) and 10(b)). The Siberian High presents the north-south seesaw 


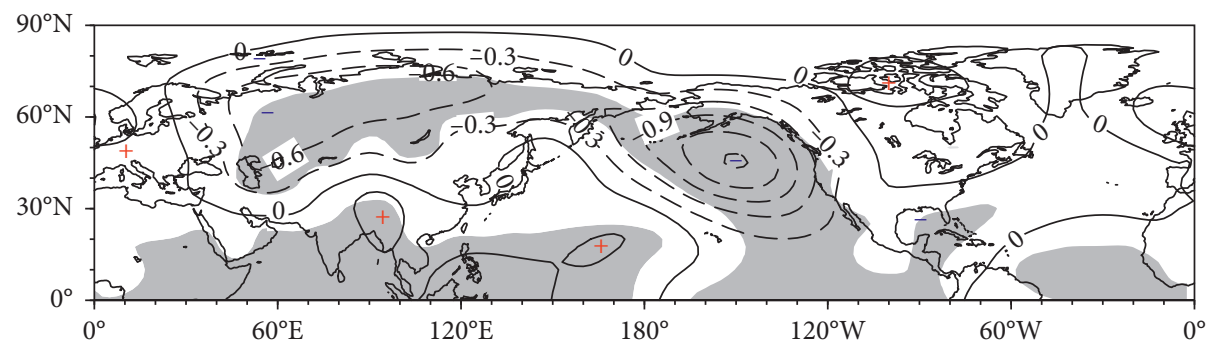

(a)

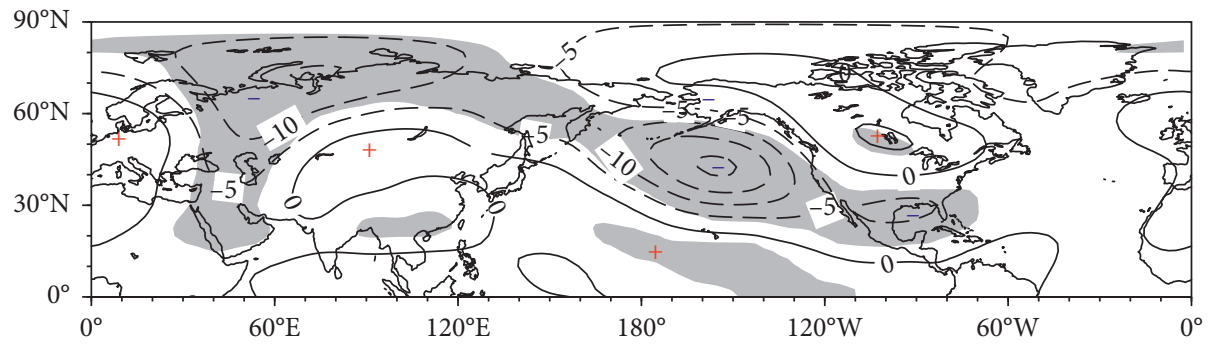

(b)

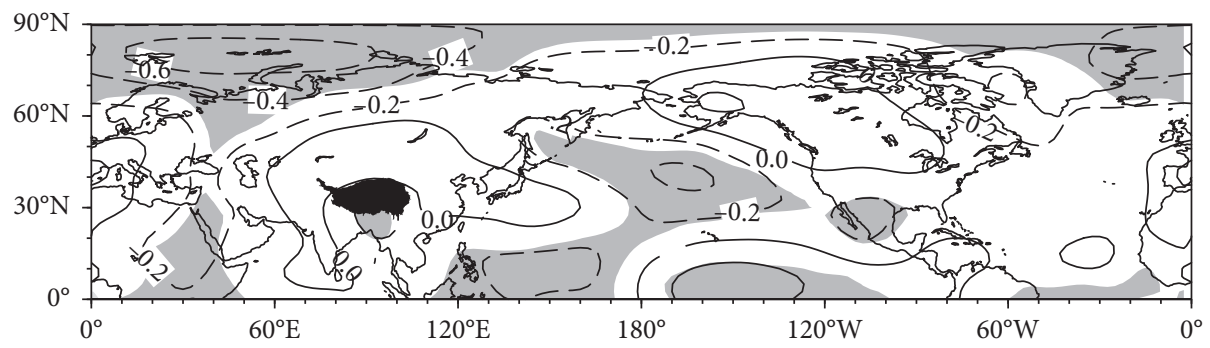

(c)

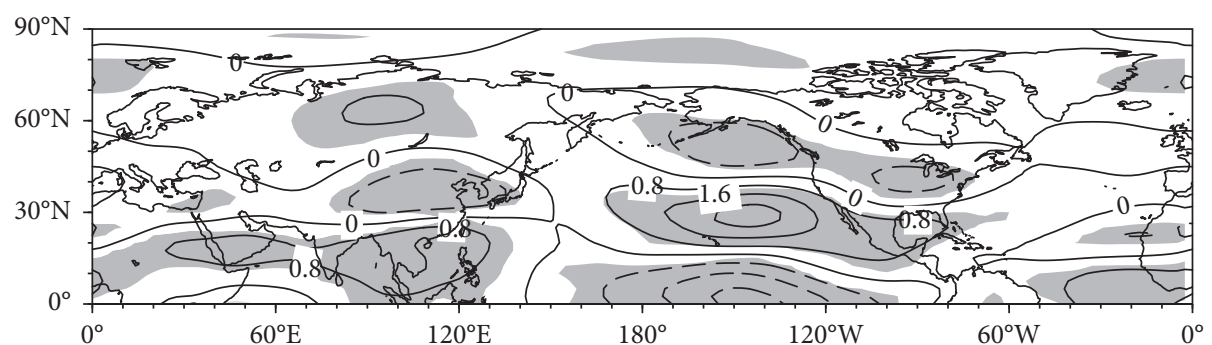

(d)

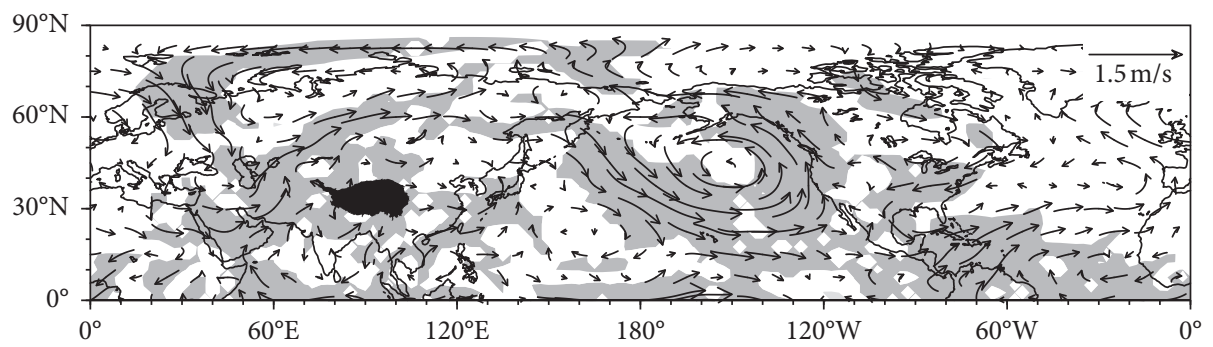

(e)

Figure 9: The same as in Figure 7 but for $I_{\mathrm{NP}}$ in winter.

anomaly (Figure 10(a)), and a ridge lies between Lake Balkhash and Lake Baikal (Figure 10(b)). The East Asian temperate is stronger and subtropical jet is weaker (Figure 10(d)). There is a cold air stack between Victoria Island and the Greenland Sea (Figure 10(c)). The configuration of upper and lower circulation systems is conducive to the arrival of cold air to in North China from the Greenland Sea, East European Plain, West Siberia, and west of Lake Baikal (Figure 10(e)), resulting in frequent ECEs. 


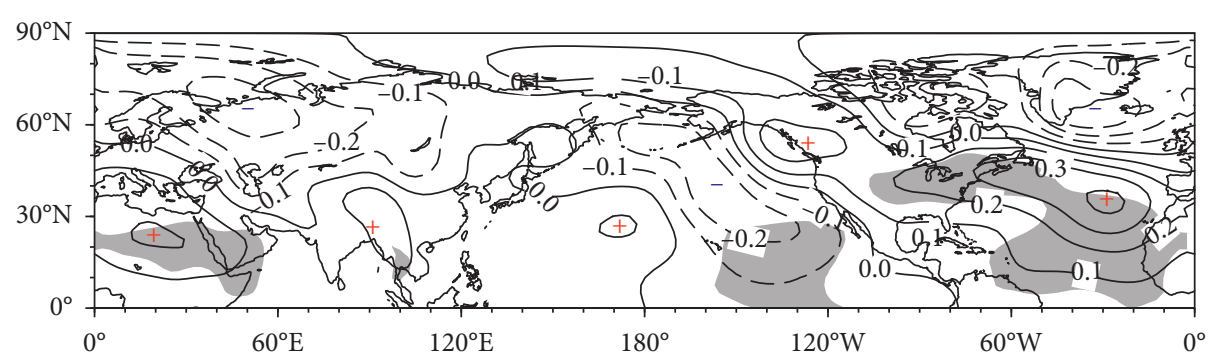

(a)

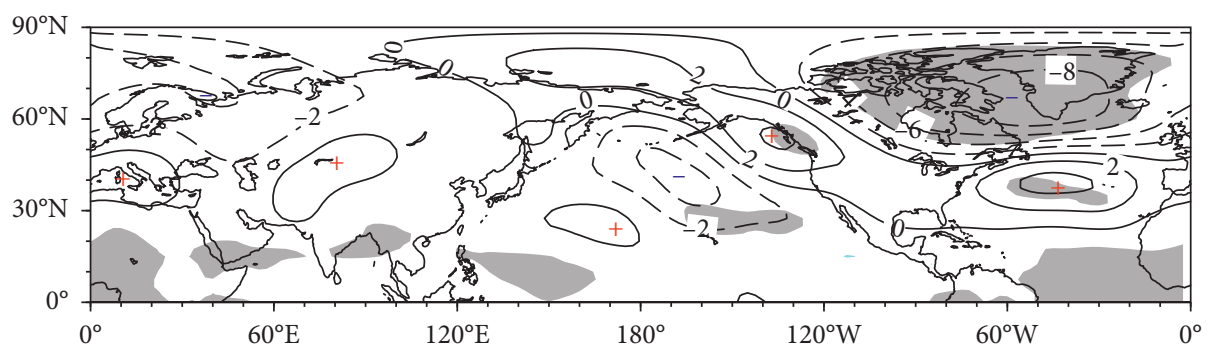

(b)

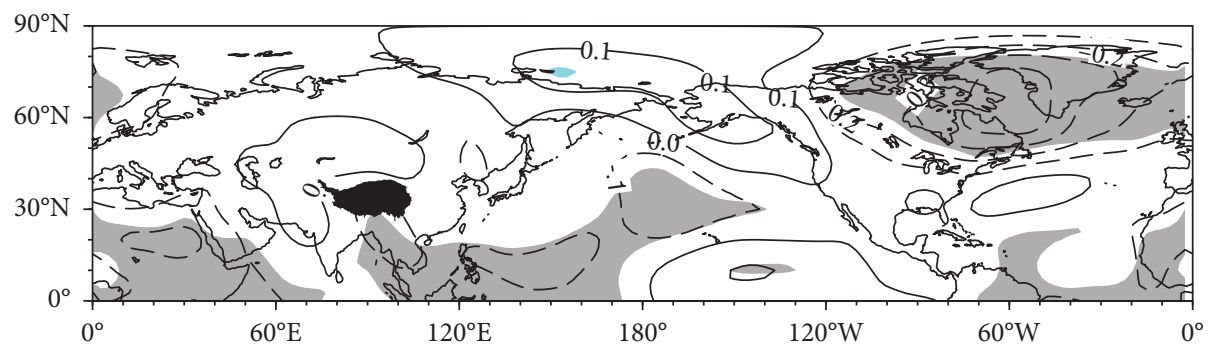

(c)

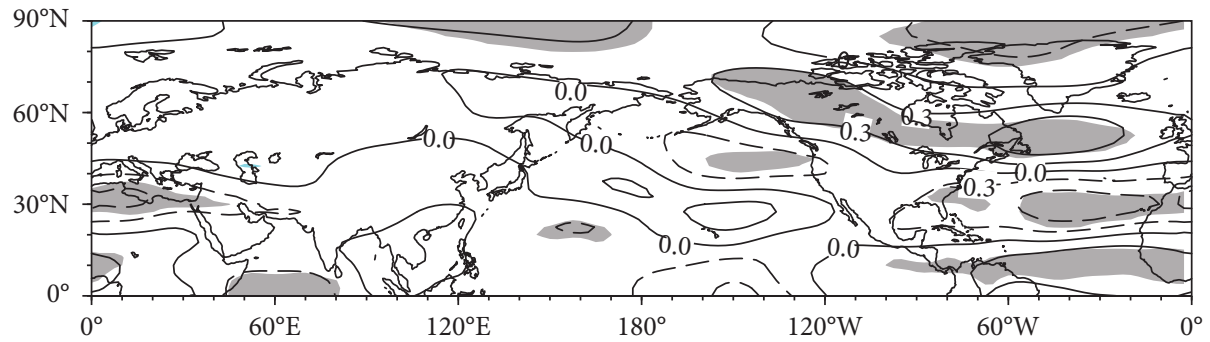

(d)

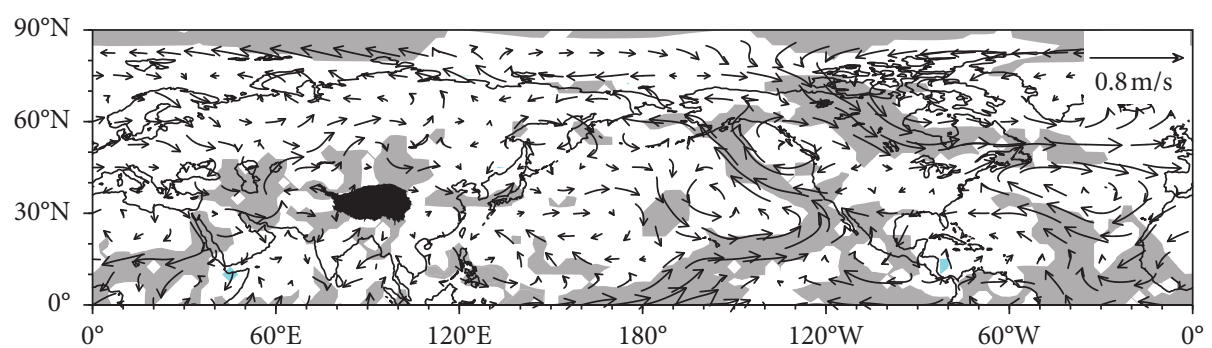

(e)

Figure 10: The same as in Figure 7 but for $I_{\mathrm{ATL}}$ in winter. 


\section{Conclusion and Discussion}

This paper analyzes the characteristics of the SSECE frequency in North China in winter. Furthermore, a possible way of SSTA in the northern mid-latitudes affecting the SSECE frequency is described. The major conclusions are given and the possible mechanism are discussed as follows.

(1) The winter SSECE frequency in North China increases gradually from southeast to northwest, decreasing before 2008 and then significantly increasing, which is caused by the SSECEs in late winter.

(2) The SSTA in the North Pacific and North Atlantic affects the winter SSECE frequency in North China by exciting atmospheric teleconnection patterns or wave trains. When the SST in the North Pacific shows an "El Niño-like" anomaly in winter, it triggers the $-\mathrm{AO},+\mathrm{PNA}$, and +EUP teleconnection patterns or wave trains in the mid-lower troposphere. Meanwhile, when the SST in the North Atlantic shows a "reversed C" negative anomaly in winter, it triggers + NAO, +PNA-like, and +EUP-like patterns. Together, the two deepen the Urals trough and strengthen the ridge to the south or southwest of Lake Baikal. Consequently, the Siberian High is weaker in the north and stronger in the south. Along with the weaker subtropical jet in the upper troposphere and the stronger East Asia winter monsoon, these factors cause cold air to invade North China, resulting in frequent SSECEs in North China.

Zhu et al. [35] indicated that when the Siberian High is abnormally weak in the north and strong in the south, the northeast part of East Asia is colder and vice versa, which is consistent with our conclusion. In this paper, it is further pointed out that the interannual anomalies of the Siberian high seesaw are related not only to AO, PNA, and EUP teleconnection waves induced by ENSO-type SSTA in the North Pacific Ocean, but also to NAO, PNA-type, and EUP teleconnection waves induced by inverted C-type SSTA in the North Atlantic Ocean.

(3) When a negative SSTA develops from the tropical northwest Pacific to the central North Pacific from summer to fall and the SSTA shows an "El Niño-like" development trend, the SSECE frequency will be higher in winter.

(4) A possible mechanism for the impacts of the northern mid-latitude SSTA on the winter SSECE frequency in North China is discussed and speculated below.

The previous research showed that the interdecadal variation of the mid-latitude air-sea system in the northern hemisphere may have a coupling mechanism of "two oceans and one atmosphere" [36, 37]. Liu and Song [31] pointed out that the positive (negative) SSTA in the eastern (Midwest) part of the North Pacific triggered an anomalous circulation similar to Figure 8(b) in the North Pacific-North AmericaNorth Atlantic in autumn, resulting in the circulation anomaly over the North Atlantic Ocean, and then the atmosphere forced the ocean, which caused the North Atlantic Ocean to store this anomalous signal in autumn. Then, the Atlantic-Eurasian teleconnection pattern anomaly affects the circulation in the East Asian region through the energy dispersion of upstream and downstream fluctuation in winter $[38,39]$, thereby affecting the temperature in winter in China [40].

Sections 4.2 and 4.3 indicate that the SSTAs in the North Pacific and North Atlantic have combined effects on the atmospheric circulation anomalies and jointly affect the SSECE frequency in North China. Combined with the above existing research results, the possible mechanism of northern mid-latitude SSTA affecting the winter SSECE frequency in North China is speculated: the negative SST anomalies in the Midwest part of North Pacific excite the teleconnection wave train in the North Pacific-North America-North Atlantic-Eurasia in summer and autumn, and then the atmosphere forces the ocean, resulting in the North Atlantic storing these atmospheric signals. In winter, the persistent SST anomalies in the North Pacific and North Atlantic interact with each other, and their superposition enhances the Eurasian teleconnection wave train. The upstream wave energy disperses downstream, and the wave train centers move eastward from summer to winter, leading to an increase of the SSECEs frequency in North China. Of course, further time scale separation [41], dynamic diagnosis, and simulation verification are needed to support this speculation.

\section{Data Availability}

The data used to support the findings of this study are available from the corresponding author upon request.

\section{Conflicts of Interest}

The authors declare that there are no conflicts of interest regarding the publication of this article.

\section{Acknowledgments}

This research was supported jointly by the National Key R\&D Program of China (2018YFC1505602) and NSFC (41790471). The authors acknowledge the United States National Centers for Environmental Prediction/National Center for Atmospheric Research for providing the reanalysis data.

\section{References}

[1] H.-G. Ove, D. Jacob, M. Taylor et al., "Impacts of $1.5^{\circ} \mathrm{C}$ global warming on natural and human systems," in An IPCC Special Report on the Impacts of Global Warming of $1.5^{\circ} \mathrm{C}$ above Preindustrial Levels and Related Global Greenhouse Gas Emission Pathways, in the Context of Strengthening the Global Response to the Threat of Climate Change, Sustainable Development, and Efforts to Eradicate Poverty, Intergovernmental Panel on Climate Change, Geneva, Switzerland, 2018, https://www. ipcc.ch/sr15/download/\#chapter. 
[2] C.-Y. Zhang and Y.-C. Zhang, "The characteristics of east Asian jet stream in severe snow storm and freezing rain processes over Southern China in early 2008," Journal of Tropical Meteorology, vol. 29, no. 2, pp. 306-314, 2013.

[3] C.-H. Sun, F.-M. Ren, B. Zhou et al., "Features and possible causes for the low temperature in winter 2011/2012," Meteorology Monthly, vol. 38, no. 7, pp. 884-889, 2012.

[4] F.-H. Hang, H.-S. Chen, and H.-D. Ma, "Interdecadal variation in the relationship between North Atlantic oscillation and extreme low temperature over Northern China in winter," Chinese Journal of Atmospheric Sciences, vol. 42, no. 2, pp. 239-250, 2018.

[5] B.-Y. Wu, "Two extremely cold events in East Asia in January of 2012 and 2016 and their possible associations with Arctic warming," Transactions of Atmospheric Sciences, vol. 42, no. 1, pp. 16-29, 2019.

[6] L.-Y. Zhu and J. Jiang, "The intraseasonal characteristics of wintertime persistent cold anomaly in China and the role of low frequency oscillation in the low latitude and midlatitude," Journal of Tropical Meteorology, vol. 29, no. 4, pp. 649-655, 2013.

[7] T. Ding, W.-H. Qian, and Z.-W. Yan, "Characteristics and changes of cold surge events over China during 1960-2007," Atmospheric and Oceanic Science Letters, vol. 2, no. 6, pp. 339-344, 2009.

[8] J. Liu, X.-F. Xu, and H. Luo, "An empirical research on the impacts of extreme weather and climate events on agricultural economic output in China," Scientia Sinica Terrae, vol. 42, no. 7, pp. 1076-1082, 2012.

[9] Y.-H. Ding, "Build-up, air mass transformation and propagation of Siberian high and its relations to cold surge in East-Asia," Meteorology \& Atmospheric Physics, vol. 44, pp. 281-292, 1990.

[10] L.-R. Lan and D.-L. Li, "Interannual and interdecadal anomaly features of Siberian high and their impact on winter temperature of China," Plateau Meteorology, vol. 35, no. 3, pp. 662-674, 2016.

[11] D.-Q. Zhang and W.-L. Song, "Northern hemisphere atmospheric circulation characteristics in 2017/2018 winter and its impact on weather and climate in China," Meteorological Monthly, vol. 44, no. 7, pp. 969-976, 2018.

[12] Y. Zhang, K. R. Sperber, and J. S. Boyle, "Climatology and interannual variation of the east asian winter monsoon: results from the 1979-95 NCEP/NCAR reanalysis," Monthly Weather Review, vol. 125, no. 10, pp. 2605-2619, 1997.

[13] S.-L. Hu, Y. Li, C.-X. Fang et al., "The relationship between ural blocking, Siberia high and the east asian winter monsoon," Journal of Lanzhou University: Natural Sciences, vol. 54, no. 4, pp. 440-452, 2018.

[14] Y. Jin, H.-M. Yan, S.-Y. Yang et al., "Relationship between wintertime thermal variation over the Eurasia and siberian high," Journal of Meteorological Sciences, vol. 32, no. 5, pp. 542-549, 2012.

[15] S.-Y. Tao, "A study of East Asian cold wave in China in the past decade," Acta Meteorologica Sinica, vol. 30, no. 3, pp. 226-230, 1959.

[16] Z.-Y. Wang and Y.-H. Ding, "Climate change of the cold wave frequency of China in the last 53 years and the possible reasons," Chinese Journal of Atmospheric Sciences, vol. 30, no. 6, pp. 1068-1076, 2006.

[17] W.-H. Qian and W.-W. Zhang, "Changes in cold wave events and warm winter in China during the last 46 years," Chinese Journal of Atmospheric Sciences, vol. 31, no. 6, pp. 1266-1278, 2007.
[18] D. Si, Q.-Q. Li, Y.-J. Liu et al., "Possible causes for the anomalous weak East Asian winter monsoon in 2013/2014," Meteorological Monthly, vol. 40, no. 7, pp. 891-897, 2014.

[19] D. Ye and Y.-C. Zhang, "Association of concurrent variation between the East Asian polar front and subtropical jets with winter cold air activity in China," Chinese Journal of Atmospheric Sciences, vol. 38, no. 1, pp. 146-158, 2014.

[20] F.-Y. Wei, "The change characteristics of cold wave disasters in China under the background of climate warming," Progress in Natural Science, vol. 18, no. 3, pp. 289-295, 2008.

[21] B.-Y. Wu and J. Wang, "Possible impact of winter arctic oscillation on Siberian high, the east Asian winter monsoon and sea-ice extent," Advances in Atmospheric Sciences, vol. 19, no. 2, pp. 297-320, 2002.

[22] W. Chen and L.-H. Kang, "Linkage between the arctic oscillation and winter climate over East Asia on the interannual timescale: roles of quasi-stationary planetary waves," Chinese Journal of Atmospheric Sciences, vol. 30, no. 5, pp. 863-870, 2006.

[23] W. Chen, X. Lan, L. Wang, and Y. Ma, “The combined effects of the ENSO and the Arctic Oscillation on the winter climate anomalies in East Asia," Chinese Science Bulletin, vol. 58, no. 12, pp. 1355-1362, 2013.

[24] D. Si, L.-J. Ma, P.-L. Wang et al., "Anomalous activity of Arctic oscillation in winter 2015/2016 and its impact on temperature in China," Meteorological Monthly, vol. 42, no. 7, pp. 892-897, 2016.

[25] B.-Y. Wu and R.-H. Huang, "Effects of the extremes in the north atlantic oscillation on East Asia winter monsoon," Chinese Journal of Atmospheric Sciences, vol. 23, no. 6, pp. 641-651, 1999.

[26] L.-R. Lan and D.-L. Li, "Relationship between the intensity of the Siberian high and the SST anomaly in the north Atlantic," Transactions of Atmospheric Science, vol. 40, no. 1, pp. 13-24, 2017.

[27] X.-C. He, Q.-P. Li, Y.-H. Ding et al., "Numerical simulation of East Asian winter monsoon with ENSO episodes using a regional climate model," Acta Meteorologica Sinica, vol. 65, no. 1, pp. 18-28, 2007.

[28] T.-C. Chen, W.-R. Huang, and J.-H. Yoon, "Interannual variation of the East Asian cold surge activity," Journal of Climate, vol. 17, no. 2, pp. 401-413, 2004.

[29] H.-M. Yan and Z.-N. Xiao, "The numerical simulation of the Indian ocean SSTA influence on climatic variations over Asian monsoon region," Journal of Tropical Meteorology, vol. 16, no. 1, pp. 18-27, 2000.

[30] F.-M. Zhao, X.-J. Zhu, F. Li et al., "Relationship between SSTA in Japan current region and temperature and precipitation in China winter," Meteorology and Environmental Sciences, vol. 30, pp. 28-31, 2007.

[31] W. Liu and W.-L. Song, "Impact of the sea surface temperature anomaly in the eastern North Pacific on interannual variations of winter temperature in northern China," Climatic and Environmental Research, vol. 23, no. 3, pp. 275-286, 2018.

[32] S.-Q. Xie and C.-H. Lu, "Intensification of winter cold events over the past 16 years in the mid-latitudes of Eurasia and their causes," Transactions of Atmospheric Sciences, vol. 41, no. 3, pp. 423-432, 2018.

[33] R. Kistler, W. Collins, S. White et al., "The NCEP-NCAR 50year reanalysis: monthly means $\mathrm{CD}$-ROM and documentation," Bulletin of the American Meteorological Society, vol. 82, no. 2, pp. 247-267, 2001.

[34] M. Ishii, A. Shouji, S. Sugimoto, and T. Matsumoto, "Objective analyses of sea-surface temperature and marine 
meteorological variables for the 20th century using ICOADS and the kobe collection," International Journal of Climatology, vol. 25, no. 7, pp. 865-879, 2005.

[35] H.-X. Zhu, W. Chen, T. Feng et al., "Interannual variations of Siberian High during boreal winter and its influence on East Asian temperature," Plateau Meteorology, vol. 38, no. 4, pp. 685-692, 2019.

[36] Y.-M. Zhu, X.-Q. Yang, Q. Xie, and Y.-Q. Yu, “The Covariant modes between Sea surface temperature in the Pacific Ocean and mid-latitude in the northern hemisphere atmospheric circulation anomalies in winter," Advances in Natural Science, vol. 18, no. 2, pp. 161-171, 2008.

[37] B. Gallego and P. Cessi, "Decadal variability of two oceans and an atmosphere," Journal of Climate, vol. 14, no. 13, pp. 2815-2832, 2001.

[38] T.-N. Palmer and Z.-B. Sun, “A modelling and observational study of the relationship between sea surface temperature in the North-West Atlantic and the atmospheric general circulation," The Quarterly Journal of the Royal Meteorological Society, vol. 111, no. 470, pp. 947-975, 1985.

[39] Y. Liu, L. Wang, W. Zhou, and W. Chen, "Three Eurasian teleconnection patterns: spatial structures, temporal variability, and associated winter climate anomalies," Climate Dynamics, vol. 42, no. 11-12, pp. 2817-2839, 2014.

[40] S. Li, "Impact of northwest Atlantic SST anomalies on the circulation over the Ural Mountains during early winter," Journal of the Meteorological Society of Japan, vol. 82, no. 4, pp. 971-988, 2004.

[41] H.-B. Wu and L. Wu, Diagnosis and Prediction Method of Climate Variability, China Meteorological Press, Beijing, China, 2005. 